\title{
An Effective Method of Segregation of Losses in Distribution Systems
}

\author{
Asanka S. Rodrigo and M.D.P.R. Gunatillaka
}

\begin{abstract}
Power system losses have turned out to be a major challenge for electricity utilities worldwide. Bulk of the losses in power system occurs in electricity distribution. The overall energy loss and the distribution system loss in the Sri Lanka power system were about 10\% in 2016. Before formulating strategies for loss reduction, it is essential to segregate and determine the losses at each level. Once losses are segregated, utilities can clearly identify their priorities and launch effective programmes to arrest losses.
\end{abstract}

This paper discusses a method to segregate losses in a selected area of the electricity distribution system, Sri Lanka. The electricity distribution network in Gampaha district, Sri Lanka that belongs to the Ceylon Electricity Board(CEB), was selected for the study. Accordingly, the losses were segregated into medium voltage network loss, losses in distribution transformers and low voltage network loss. A study was also carried out to further segregate losses into technical and non-technical components in the low voltage networks of two distribution substations. Technical losses were estimated and thereby non-technical losses were derived. Test results of electricity meters were also analysed to assess contribution to Non-Technical Losses (NTL).

Keywords: Distribution loss, Technical Loss, Non-technical loss, Load factor, Load loss factor

\section{Introduction}

Energy loss in an electric power system is the difference between energy input to the system and the energy billed on the consumption of consumers connected to that particular power system. Losses in electric power systems are unavoidable. In the present global picture, where there is a never increasing demand for energy, energy loss in any power system raises concerns to the utility, society, as well as the country as a whole where it belongs to. It has significant economical, financial and societal impacts amidst the continuing global energy crisis.

Energy losses occur at different levels of the power system, namely in electricity generation, transmission and distribution. Utilities worldwide are implementing various strategies and measures to minimize losses in power systems. It is in fact a scenario where continual, diverse and time variant efforts and strategies are essential to maintain losses at certain minimum levels.

Electricity transmission and distribution losses in Sri Lanka were much higher before the year 2000. However, a significant reduction in the losses is noticed thereafter [1]. At present, the level of transmission and distribution losses in the country remains around $14 \%$ of the gross electricity generation. Transmission and distribution losses in developed countries range from $4-12 \%$ [2]. Table 1 shows the variation of gross electricity generation, total power system losses, and transmission and distribution (T\&D) losses in the country from 1992 to 2010. The total losses include the electricity consumption for the own use of power plants in addition to the transmission and distribution losses. Table 1 shows variation of T\&D losses in Sri Lanka [1].

The energy loss in the Sri Lanka transmission network in 2012 was $3.62 \%$ of the energy purchased by the transmission licensee from the generation plants [3]. Accordingly, the energy loss in the electricity distribution system in the country was around $10 \%$ of electrical energy purchased from the transmission licensee in 2016. Therefore, it is evident that the losses in the country's power system are predominant in the electricity distribution system. Therefore, more attention is required to reduce distribution losses in view of reducing overall losses in the country's power system.

Eng. (Dr.) Asanka. S. Rodrigo, BSc. Eng(Moratuwa), MSc (Moratuwa), PhD(HKUST), AMIE (Sri Lanka), Senior Lecturer in Electrical Engineering, University of Moratuwa. Email:asankar@uom.lk

ORCID ID: http://orcid.org/0000-0001-6759-2782

Eng. M.D.P.R. Gunathilaka, BSc. Eng(Moratuwa), MSc (Moratuwa), CEng. MIE (Sri Lanka), Chief Engineer, Ceylon Electricity Board.

Email:ravindragunatillaka@gmail.com

ORCID ID: http://orcid.org/0000-0003-3921-6645 
Table 1 - Variation of Transmission and Distribution (T\&D) losses

\begin{tabular}{|c|c|c|c|}
\hline Year & $\begin{array}{c}\text { Gross } \\
\text { Generation } \\
\text { in GWh }\end{array}$ & $\begin{array}{c}\text { Total } \\
\text { Losses as } \% \\
\text { of Gross } \\
\text { Generation }\end{array}$ & $\begin{array}{c}\text { T\&D Losses } \\
\text { as \% of } \\
\text { Gross } \\
\text { Generation }\end{array}$ \\
\hline 1995 & 4,800 & 20.17 & 19.56 \\
\hline 1996 & 4,529 & 18.84 & 17.34 \\
\hline 1997 & 5,144 & 19.12 & 17.49 \\
\hline 1998 & 5,675 & 19.80 & 18.29 \\
\hline 1999 & 6,357 & 21.94 & 19.96 \\
\hline 2000 & 7,050 & 22.75 & 20.34 \\
\hline 2001 & 6,945 & 20.85 & 18.45 \\
\hline 2002 & 7,223 & 20.20 & 18.03 \\
\hline 2003 & 8,140 & 19.05 & 17.89 \\
\hline 2004 & 8,780 & 17.14 & 15.53 \\
\hline 2005 & 8,884 & 18.70 & 17.48 \\
\hline 2006 & 9,535 & 17.78 & 16.37 \\
\hline 2007 & 9,938 & 17.04 & 15.40 \\
\hline 2008 & 9,998 & 16.40 & 14.70 \\
\hline 2009 & 9,964 & 16.03 & 14.37 \\
\hline 2010 & 10,718 & 14.78 & 13.87 \\
\hline 2011 & 11,528 & 13.10 & 11.72 \\
\hline 2012 & 11,801 & 11.20 & 10.67 \\
\hline 2013 & 11,962 & 11.20 & 10.76 \\
\hline 2014 & 12,418 & 10.90 & 10.47 \\
\hline 2015 & 13,154 & 10.40 & 9.96 \\
\hline & & & \\
\hline
\end{tabular}

Distribution losses consist of electrical energy losses at different levels and different forms in the distribution system. In this context, segregation of distribution losses is very important to identify the losses at each level. When the losses are segregated, the distribution network utility can formulate strategies and take corrective measures to reduce losses at different levels and in different forms, and thereby effectively reduce the overall distribution losses.

\section{Electricity Distribution System in Sri Lanka}

Table 2 shows the performance of the distribution licensees (DLs) in Sri Lanka for the year 2012. Estimated energy consumption of street lamps in each licensee has been added as energy sales in calculating the losses.

Table 2 - Performance of Distribution Licensees in 2012

\begin{tabular}{|l|c|c|}
\hline Distribution licensee & $\begin{array}{c}\text { Percentage } \\
\text { loss }\end{array}$ & $\begin{array}{c}\text { Loss in } \\
\text { GWh }\end{array}$ \\
\hline CEB Region 1 & 7.7 & 242.4 \\
\hline CEB Region 2 & 9.5 & 312.0 \\
\hline CEB Region 3 & 11.5 & 251.3 \\
\hline CEB Region 4 & 8.1 & 116.6 \\
\hline $\begin{array}{l}\text { Lanka Electricity } \\
\text { Company (LECO) }\end{array}$ & 4.4 & 57.9 \\
\hline
\end{tabular}

\subsection{Electricity Distribution Systems}

The part of the power system which distributes electrical energy for local use is termed as the distribution system. It is the electrical system between the grid substations fed by the transmission network and the meters of the end consumers.

Modern distribution utilities have to operate their systems at stipulated voltage levels, provide required power demands, and maintain high levels of reliability. Whilst doing that, they have to make every effort to minimize all forms of losses in order to sustain their business in an era of energy crisis.

\subsection{Electricity Distribution in Sri Lanka}

The electricity distribution in Sri Lanka is done by two organizations, namely, Ceylon Electricity Board and Lanka Electricity Company. Primary distribution is done mainly at $33 \mathrm{kV}$ level by CEB. Figure 1 illustrates the major components and the electrical energy flow in the electricity distribution system.

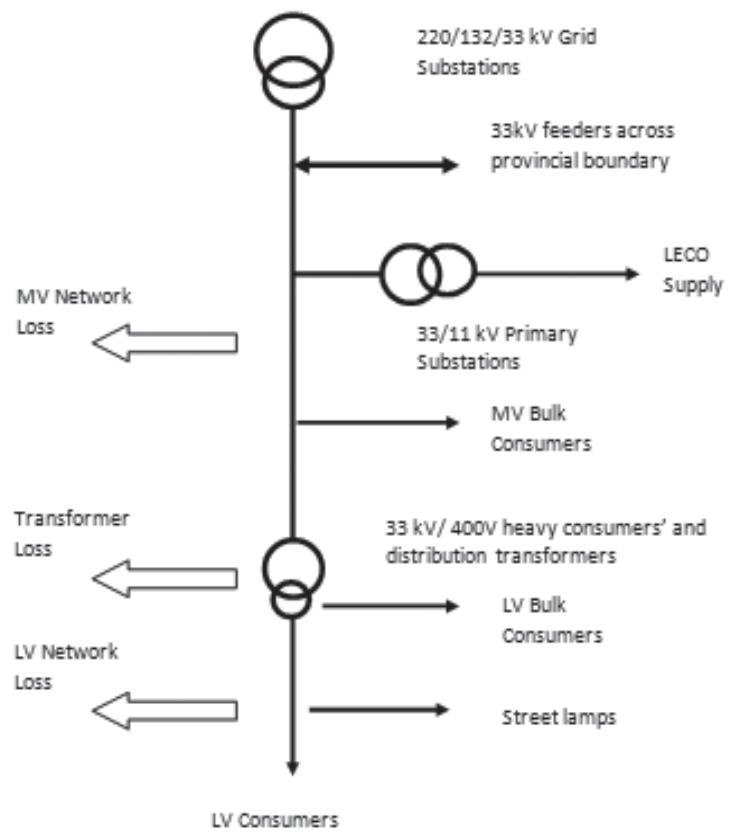

Figure 1 - Energy flow in the distribution system

\subsection{Distribution Losses}

Distribution losses can be segregated into the following components.

- Technical losses

- Non-technical losses 


\subsubsection{Technical losses}

Technical losses are internal to the power system. Technical losses in the system are inherently influenced by components and system designs. A list of such components in the local distribution system where power dissipation occurs is mentioned below.

- MV distribution lines

- Transformers supplying to low voltage heavy consumers

- Distribution transformers

- Low voltage distribution lines

- Consumer service lines

- Voltage regulators

- Capacitors

- Electrical burdens in metering equipment

- All other electrical devices necessary for the operation of the distribution system

The losses in the power distribution lines, including service lines, are due to conductor loss. There are energy losses in electricity meters too. Further, higher level of harmonics in a distribution system also increases losses. Technical losses can be accurately computed provided the load conditions in the power system are known. Typically, load flow studies or network simulations are used to calculate technical losses.

\subsubsection{Non-technical losses (NTLs)}

NTLs are due to actions external to the power distribution system. NTLs are often unaccounted by utilities due to unavailability or lack of information. Hence, it is extremely difficult to have an accurate estimation of NTL in distribution systems. The general practice is to derive NTL after estimating technical losses.

NTLs represent an avoidable financial loss for the utility. It is the amount of energy not billed but consumed. NTLs also reflect a social issue. The consumers who are accurately metered and billed are subsidizing those who do not pay for the electricity consumed. In general, NTL in the electricity distribution is high in countries where Gross Domestic Product (GDP) per capita is low. However, there are exceptions such as Thailand and Indonesia who have achieved very low levels of NTL irrespective of lower GDP per capita [5].

\subsubsection{Electricity theft}

Electricity theft can be defined as a conscious attempt by a person to eliminate or reduce the amount of money that he or she will owe the utility for electrical energy consumed. It is generally viewed as the major source of NTL by the electricity utilities worldwide. Two main forms of electricity theft can be identified, namely, directly connecting an unmetered load to a power line and tampering with the electricity meter in order to reduce, or stop recording the actual energy consumed.

Direct connections to power lines are much easier and safer in low voltage electricity distribution systems. Illegal direct connections are mostly detected in rural and shanty areas. Tampering with electricity meters is probably the most common form of electricity theft in Sri Lanka. The present technology of electromechanical meters used for metering low voltage electricity consumers is very old. The public is familiar with the technology and working principle of electro-mechanical meters.

\subsubsection{Other forms of Non-technical losses}

Whilst electricity theft is considered as the major form of NTL, the other forms of NTL are,

- Defective energy meters

- Un-metered connections

- Errors and delays in meter reading

- Arranging false meter readings by bribing utility staff

- $\quad$ Errors in billing

- Assessed meter readings

- Errors in estimation of technical losses

\subsection{Economic Impact of Losses}

Energy losses represent losses in revenue for utilities. To recover costs involved in the supply of electricity and to fill the utility viability gap, costs of losses should be covered by paying users or by the Government via targeted output-based subsidies.

Loss reduction and improvement on energy efficiency would partially cover the expected demand rise offsetting the need to increase the installed capacity. On the supply side, the impact on the utility to finance new generation capacity can be delayed or avoided if reduction in demand can be achieved by implementing good demand side management measures. The use of energy efficient compact fluorescent lamps (CFLs) in place of conventional incandescent lamps at large scale for domestic and other lighting applications is a typical example of such a demand side management measure. 
Table 3 - Consumer details and energy sales in WPN [6]

\begin{tabular}{|c|c|c|c|c|}
\hline \multirow{2}{*}{$\begin{array}{c}\text { No. of } \\
\text { Consumers }\end{array}$} & \multicolumn{2}{|c|}{ Energy Sales (GWh/Yr) } & Revenue \\
\cline { 2 - 5 } & $\begin{array}{c}\text { LV } \\
\text { consumers }\end{array}$ & $\begin{array}{c}\text { MV \& LV } \\
\text { bulk } \\
\text { consumers }\end{array}$ & Total & $\begin{array}{c}\text { Million } \\
\text { LKR/Yr }\end{array}$ \\
\hline 542,942 & 606 & 1,104 & 1,710 & 25,765 \\
\hline
\end{tabular}

\subsection{Reduction of distribution losses}

Reduction of losses in electrical power systems is vital because of the ever increasing demand for energy and the fast depletion of energy sources. It benefits the consumer, utility and country as a whole. However, in order to implement loss reduction measures effectively, it is essential to segregate the distribution losses with sufficient accuracy.

Increased revenue through reduction of NTL is a financial boost for any utility since the investments involved in implementing NTL reduction programmes are much less than implementing technical loss reduction programmes. Further, when the consumers who consume electricity illegally have to pay for their actual consumption, they will adjust their consumption to match their capacity to pay. This reduces the energy demand, which will create the same effect as reducing technical losses.

\subsection{Case Study of Western Province North (WPN)}

2.6.1 Overview of distribution system in WPN Western Province North (WPN) is one of the three provinces in the Distribution Division 2 (DL 2) of Ceylon Electricity Board. The distribution system of the WPN spreads geographically over Gampaha district in Sri Lanka. Important facts about the province are shown in Table 4.

Table 4 - Statistical data on WPN distribution system [6]

\begin{tabular}{|l|r|}
\hline Land area & $1,387 \mathrm{~km}^{2}$ \\
\hline Population & 2.29 Million \\
\hline No. of Households & 475,929 \\
\hline $\begin{array}{l}\text { Percentage of } \\
\text { Electrified Houses }\end{array}$ & $100 \%$ \\
\hline Peak Power Demand & $456 \mathrm{MW}$ \\
\hline Energy Demand (Sales) & $2,146 \mathrm{GWh} / \mathrm{Yr}$ \\
\hline
\end{tabular}

A noticeable fact in the distribution system in WPN is that approximately $65 \%$ of electricity sales are from heavy or bulk consumers. Only $35 \%$ of energy is sold to low voltage ordinary consumers. However, there were only 1,200 bulk consumers in WPN.

\subsubsection{Distribution losses in WPN}

The electricity distribution losses in WPN as a percentage of energy input to the system have been at $7.7 \%, 7.6 \%$ and $7.3 \%$ in 2010,2011 and 2012 respectively [6][7]. Table 5 presents results of meter testing programme carried out in the province during the recent past.

Table 5 - Results of meter testing in WPN

\begin{tabular}{|l|c|c|}
\hline & $\begin{array}{c}\text { Number } \\
\text { of meters }\end{array}$ & $\begin{array}{c}\text { Percentage } \\
\text { of meters } \\
\text { tested }\end{array}$ \\
\hline Tested & 53,818 & 100.0 \\
\hline Accuracy acceptable & 48,300 & 89.7 \\
\hline $\begin{array}{l}\text { Accuracy not } \\
\text { acceptable } \\
\text { (Defective) }\end{array}$ & 3,914 & 7.3 \\
\hline $\begin{array}{l}\text { Physical adjustments } \\
\text { done }\end{array}$ & 826 & 1.5 \\
\hline By-passed & 76 & 0.1 \\
\hline Meters damaged & 629 & 1.2 \\
\hline $\begin{array}{l}\text { Direct connections } \\
\text { before meter }\end{array}$ & 73 & 0.1 \\
\hline Total cases for NTL & 5,518 & 10.3 \\
\hline
\end{tabular}

The presence of defective meters is quite significant. More than $10 \%$ of the meters tested contributed to NTL.

\section{Modelling and Estimation of Distribution Losses}

Medium voltage network, power distribution transformers and low voltage network are three major components of concern. There are different models and techniques which can be used for the estimation of losses with acceptable level of accuracy. Some of the commonly applied models and techniques are discussed in detail in this section.

\subsection{Medium Voltage Network}

The peak power loss of the MV network is calculated through load flow studies. The loss of energy in any electricity network varies with time. A hypothetical time known as 'Utilization time of losses' or 'UTL' is defined such that losses during UTL with a continuous load equal to the peak power loss is the same as the loss with actual loading over the day[12], [13]. 
An empirical formula known as Jung's formula is used to calculate UTL [7], [8].

$$
\begin{array}{r}
\text { Load Factor }(\mathrm{LF})=\frac{\text { Average Demand }}{\text { Peak Demand }} \\
\text { Utilization Time of Loss }(\mathrm{UTL})=\frac{L F^{2}\left(2+L F^{2}\right) \times 8760}{(1+2 . L F)} \\
\therefore \text { Annual Energy Loss }=(\text { Peak Power Loass }) \times \text { UTL per year }
\end{array}
$$

\subsection{Power Distribution Transformers}

\subsubsection{Load loss factor and estimation of energy loss}

Energy loss of a transformer depends on how it is loaded over a period of time. The following terms are important in understanding the energy loss of transformers.

Load loss factor (LLF)

$=\frac{\text { Average power loss }}{\text { Peak powerloss }}$

$=\frac{\text { Actual loss }(\mathrm{kWh}) \text { during the period }}{\text { Loss at maximum current during the period in } \mathrm{kWh}}$

The average power loss of a transformer is given by,

Power loss $=$ LI + LC [9]

Where,

LI - Iron loss of the transformer

LC - Copper loss of the transformer

Utilization Factor (UF) of a transformer is defined as follows.

$$
\begin{aligned}
\text { UF } & =\frac{\text { Maximum demand }}{\text { Rated capacity }} \\
& =\frac{\text { Current at maximum demand }}{\text { Current at rated capacity }}
\end{aligned}
$$

When the copper loss at the rated full load capacity of the transformer is denoted by $L C_{R}$, copper loss at maximum demand $\left(\mathrm{LC}_{\mathrm{m}}\right)$ of the transformer is given by,

$\mathrm{LC}_{\mathrm{m}}=\mathrm{LC}_{\mathrm{R}} \times(\mathrm{UF})^{2}$

Therefore, the average variable loss of a transformer (LC) is given by,

$\mathrm{LC}=\mathrm{LC}_{\mathrm{m}} \times \mathrm{LLF}$

Therefore, energy loss of the transformer can be calculated. The relationship between load factor and load loss factor is explained by the following empirical formula [10], [11].
$\mathrm{LLF}=\mathrm{k} \times \mathrm{LF}+(1-\mathrm{k}) \times \mathrm{LF}^{2}$,

where $0.15<\mathrm{k}<0.3$

The value of coefficient $\mathrm{k}$ can be assumed or replaced with calibrated factor if metered data is available. Generally $\mathrm{k}=0.2$ is used by utilities to calculate losses of distribution transformers [9], [10], [11].

\subsubsection{Calculating energy loss of a large number of transformers}

Instead of calculating the losses of individual transformers, a statistical method can be applied to approximately calculate the total loss of all the transformers under consideration. However, the following details of the transformers are required for the calculation.

- Capacity rating of each transformer

- Peak loading of each transformer

- Fixed and variable losses of the transformers of each rating

- Load factor

Table 6 is used to approximately determine the total losses of the transformers of a given rating.

Table 6 - Calculation of losses in transformers

\begin{tabular}{|c|c|c|c|}
\hline $\begin{array}{c}\text { Percentage } \\
\text { Loading } \\
(\mathrm{X})\end{array}$ & $\begin{array}{c}\text { No. of } \\
\text { transformers } \\
(\mathrm{f})\end{array}$ & $(\mathrm{X} / 2)$ & $(\mathrm{X} / 2)^{*} \mathrm{f}$ \\
\hline $0-20$ & & 10 & \\
\hline $20-40$ & & 30 & \\
\hline $40-60$ & & 50 & \\
\hline $60-80$ & & 70 & \\
\hline $80-100$ & & 90 & \\
\hline Total & $\sum \mathrm{f}=$ & & $\sum\left(\mathrm{X} / 2{ }^{*} \mathrm{f}\right)=$ \\
\hline
\end{tabular}

The average loss of a transformer of a given rating such as $100 \mathrm{kVA}, 250 \mathrm{kVA}$ etc. is given by,

Average loading of a transformer or average,

$\mathrm{UF}=\frac{\sum(\mathrm{X} / 2) \times \mathrm{f}}{\sum \mathrm{f}}$

When LF is known, LLF can be calculated using value $\mathrm{k}=0.2$ which is generally accepted. Then, average power loss of a transformer can be calculated. Then the total power loss of all the transformers of a given rating is calculated by multiplying average power loss of a transformer by the number of transformers. The calculations are repeated for each available rating of the distribution transformers. 


\subsection{Low Voltage Distribution Network}

\subsubsection{Overview of low voltage network}

LV feeders consist of un-transposed three phase, two phase or single phase line segments. They supply electricity to balanced or unbalanced three phase loads, two phase loads and single phase loads. As a result, almost all LV feeders have unbalanced voltages and currents and non-zero neutral currents.

\subsubsection{Uniformly distributed loads}

When loads are uniformly distributed along a feeder it is not necessary to model each load to determine voltage drop or power loss in the feeder. Figure 2 shows a generalized line with $n$ uniformly distributed loads.

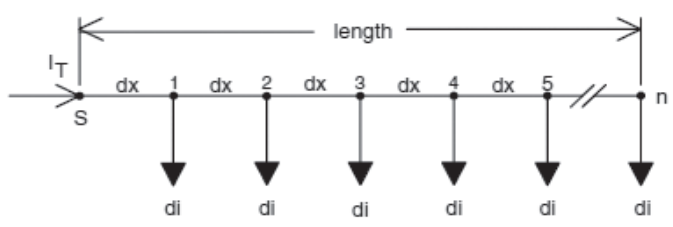

Figure 2 - Uniformly distributed loads [17]

The voltage drop along the line can be derived and shown that,

$$
V_{\text {drop }}=\operatorname{Re}\left\{\frac{1}{2} \cdot Z \cdot I_{T}\right\}
$$

The power loss in feeder can be analysed under three models.

When the model in Figure 3 is used to calculate the three phase power loss down the line, the result is,

$$
P_{\text {loss }}=3 .\left|I_{T}\right|^{2} \cdot \frac{R}{2}=\frac{3}{2} \cdot\left|I_{T}\right|^{2} \cdot R
$$

Figure 3 illustrates the model where the load is lumped at mid point.

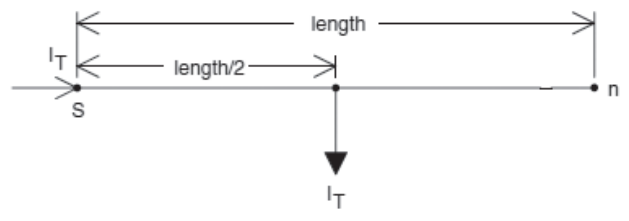

Figure 3 - Load lumped at midpoint [17]

When the model (One-half load lumped at the end) in Figure 4 is used to calculate the three phase power loss down the line, the result is,

$$
P_{\text {loss }}=3 \cdot\left|\frac{I_{T}}{2}\right|^{2} \cdot R=\frac{3}{4} \cdot\left|I_{T}\right|^{2} \cdot R
$$

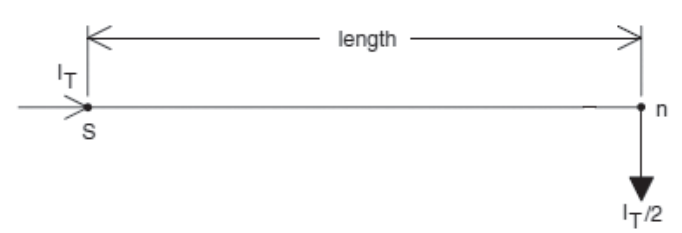

Figure 4 - One-half load lumped at end point

The two models in Figures 3 and 4 give two results for the power loss. In order to have correct results for the voltage drop as well as power loss, the exact lumped load model shown in Figure 5 can be used.

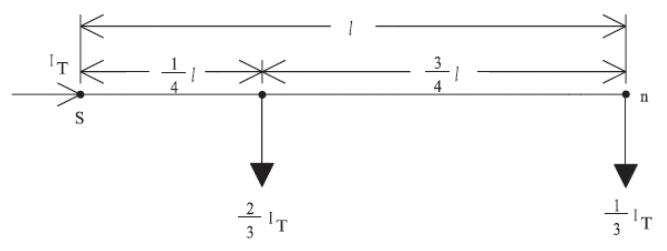

Figure 5 - Exact lumped load model [12]

\section{Estimation of Distribution Losses in WPN}

Estimation of provincial electricity distribution losses was done based on the data available in the planning division of the province. The focus in this section is to estimate the losses in the medium voltage network and the distribution transformers.

\subsection{Medium Voltage Network}

Based on the Medium Voltage Development Studies Region 2, 2012 - 2021[11], the provincial energy and power demands are as follows.

The total annual energy demand $=2,314 \mathrm{GWh}$

Peak power demand $\quad=456 \mathrm{MW}$

Peak power loss $\quad=8.32 \mathrm{MW}$

Therefore, average load factor (LF)

$$
\begin{array}{ll}
= & 2,314,000 /(456 \times 24 \times 365) \\
= & 0.579
\end{array}
$$

Using Jung's formula,

Utilization time of losses (UTL)

$$
\begin{aligned}
& =\quad \frac{0.579^{2}\left(2+0.579^{2}\right) \times 8760}{(1+2 \times 0.579)} \\
& =\quad 3,171.91 \text { hrs per year }
\end{aligned}
$$

Therefore,

Energy loss per year

$$
\begin{array}{ll}
= & 8.32 \times 3,171.91 / 1000 \\
= & 26.39 \mathrm{GWh}
\end{array}
$$

Annual energy loss as percentage of energy input to WPN,

$$
\begin{aligned}
& =26.39 / 2,314 \times 100 \% \\
& =1.14 \%
\end{aligned}
$$


4.2 Transformers of Low Voltage Bulk Consumers

The details of the LV bulk consumer transformers are shown in Table 7.

Table 7 - Details of LV bulk consumer transformers

\begin{tabular}{|l|c|c|c|c|c|c|c|}
\hline $\begin{array}{l}\text { Capacity } \\
\text { in kVA }\end{array}$ & 1,000 & 800 & 630 & 400 & 250 & 160 & 100 \\
\hline $\begin{array}{l}\text { No. of } \\
\text { units }\end{array}$ & 118 & 22 & 159 & 174 & 190 & 141 & 260 \\
\hline
\end{tabular}

The full load and no load losses of each transformer rating are shown in Table 8.

Table 8 - No load and full load losses of distribution transformers

\begin{tabular}{|l|c|c|c|}
\hline $\begin{array}{l}\text { Account } \\
\text { Number }\end{array}$ & $\mathrm{X}_{1}$ & $\mathrm{X}_{2}$ & $\mathrm{X}_{3} \sim \mathrm{Xn}_{\mathrm{n}}$ \\
\hline $\begin{array}{l}\text { Monthly } \\
\text { consumption } \\
\mathrm{kWh}\end{array}$ & 4,348 & 3,052 & \\
\hline $\begin{array}{l}\text { Maximum } \\
\text { demand } \\
\mathrm{kVA}\end{array}$ & 43 & 34 & \\
\hline $\begin{array}{l}\text { Transformer } \\
\text { capacity } \\
\mathrm{kVA}\end{array}$ & 100 & 100 & \\
\hline $\begin{array}{l}\text { Load factor } \\
\text { Load loss } \\
\text { factor }\end{array}$ & 0.160 & 0.142 & \\
\hline $\begin{array}{l}\text { Utilization } \\
\text { factor }\end{array}$ & 0.43 & 0.34 & \\
\hline
\end{tabular}

Table 9 illustrates how the LF, LLF and UF are calculated for 2 low voltage heavy consumer transformers. The data in the first three rows were obtained from the CEB billing system. There were a total of 1,043 LV heavy consumer transformers in WPN for the month of January 2012. Therefore, there would be 1,043 records (' $n$ ' number of transformers) in the Table.

Table 9 - Calculation of LF, LLF and UF of transformers

\begin{tabular}{|c|c|c|}
\hline $\begin{array}{c}\text { kVA } \\
\text { rating }\end{array}$ & $\begin{array}{c}\text { No load loss in } \\
\text { W }\end{array}$ & $\begin{array}{c}\text { Full load loss in } \\
\text { W }\end{array}$ \\
\hline 100 & 340 & 1,900 \\
\hline 160 & 460 & 2,450 \\
\hline 250 & 610 & 3,150 \\
\hline 400 & 870 & 4,000 \\
\hline 630 & 1,200 & 5,900 \\
\hline 800 & 1,300 & 8,260 \\
\hline 1,000 & 1,440 & 9,800 \\
\hline
\end{tabular}

Table 10 illustrates how the rest of the calculations were done to find the average power loss of each heavy consumer transformer.

Table 10 - Calculation of monthly energy loss of transformers

\begin{tabular}{|c|c|c|c|}
\hline Account Number & LI & LC $_{R}$ & $\begin{array}{c}\text { Energy } \\
\text { loss in } \\
\text { kWh }\end{array}$ \\
\hline 2779901918 & 340 & 1,900 & 267 \\
\hline 2779903449 & 340 & 1,900 & 260 \\
\hline
\end{tabular}

The calculations were repeated for all available bulk consumer transformers. Table 11 shows the results of calculations of monthly total energy loss of the LV heavy consumer transformers and the total energy loss.

Table 11- Energy loss of the LV bulk consumer transformers

\begin{tabular}{|l|c|}
\hline Month & Energy loss in MWh \\
\hline January & 775 \\
\hline February & 779 \\
\hline March & 735 \\
\hline April & 786 \\
\hline May & 746 \\
\hline June & 818 \\
\hline July & 797 \\
\hline August & 815 \\
\hline September & 812 \\
\hline October & 796 \\
\hline November & 814 \\
\hline December & $\mathbf{7 9 6}$ \\
\hline Total loss & $\mathbf{9 , 4 6 9}$ \\
\hline
\end{tabular}

From the provincial energy sales data, the total energy sales to LV bulk consumers was 485 GWh. Therefore, the energy loss as percentage of total annual energy input to the transformers was estimated to be 1.92 .

\subsection{Distribution Transformers (Supplying Low Voltage Consumers and Street Lamps)}

The details of electricity distribution transformers are summarized in Table 12. Based on the annual peak time load readings taken by the provincial planning branch, distribution transformers were grouped into five ranges of loading. Accordingly, the number of transformers, falling into each range of loading against their rated capacities, is also shown in Table 12. 
Table 12 - Average loading of distribution transformers

\begin{tabular}{|l|c|c|c|c|c|}
\hline $\begin{array}{l}\text { Percentage } \\
\text { Loading/ } \\
\text { Rating in } \\
\text { kVA }\end{array}$ & 630 & 400 & 250 & 160 & 100 \\
\hline $100-80$ & 1 & 10 & 50 & 186 & 77 \\
\hline $80-60$ & 7 & 11 & 88 & 235 & 77 \\
\hline $60-40$ & 1 & 20 & 93 & 273 & 74 \\
\hline $40-20$ & 2 & 15 & 59 & 136 & 65 \\
\hline $0-20$ & 7 & 24 & 26 & 43 & 48 \\
\hline Total & 18 & 80 & 316 & 873 & 341 \\
\hline
\end{tabular}

To calculate the losses, transformers of a particular capacity are first selected. Then the average loading of the selected transformers are calculated. The results of the calculation for 100 kVA transformers are shown in Table 13.

Table 13 - Calculation of average loading of transformers

\begin{tabular}{|c|c|c|c|}
\hline $\begin{array}{c}\text { Percentage } \\
\text { Loading }(\mathrm{X})\end{array}$ & $\begin{array}{c}\text { Number of } \\
\text { transformers (f) }\end{array}$ & $\mathrm{X} / 2$ & $(\mathrm{X} / 2) \mathrm{xf}$ \\
\hline $0-20$ & 48 & 10 & 480 \\
\hline $20-40$ & 65 & 30 & 1,950 \\
\hline $40-60$ & 74 & 50 & 3,700 \\
\hline $60-80$ & 77 & 70 & 5,390 \\
\hline $80-100$ & 77 & 90 & 6,930 \\
\hline Total $\left(\sum \mathrm{f}\right)$ & 341 & $\sum(\mathrm{X} / 2) \mathrm{f}$ & 18,450 \\
\hline
\end{tabular}

Average loading of a $100 \mathrm{kVA}$ transformer

$$
\begin{aligned}
& =\sum(\mathrm{X} / 2) \cdot \mathrm{f} / \sum \mathrm{f} \\
& =18,450 / 341 \\
& =54.1 \mathrm{kVA}(54.1 \% \text { of rated capacity })
\end{aligned}
$$

The no load and full load losses of a $100 \mathrm{kVA}$ transformer is $340 \mathrm{~W}$ and $1,900 \mathrm{~W}$ respectively (Ref. Table 8). The average system load factor of national grid is used for the calculations [13].

Therefore, taking LF $=0.57$,

$\mathrm{LLF} \quad=0.2 \times 0.57+0.8 \times 0.57^{2}=0.37$

Average power loss of a transformer,

$=$ No load loss $+U^{2} \times$ LLF $\times$ (Full load loss)

$=340+0.541^{2} \times 0.37 \times 1,900$

$=546 \mathrm{~W}$

Therefore,

Power loss of $100 \mathrm{kVA}$ transformers

$=546 \times 341$

$=186 \mathrm{~kW}$

The same calculations are repeated for the other available ratings of distribution transformers. The results are shown in Table 14.
Table 14 - Total power loss of the distribution transformers

\begin{tabular}{|l|c|c|c|c|c|}
\hline $\begin{array}{l}\text { Rating in } \\
\text { kVA }\end{array}$ & 630 & 400 & 250 & 160 & 100 \\
\hline $\begin{array}{l}\text { Power loss } \\
\text { per } \\
\text { transformer } \\
\text { in W }\end{array}$ & 1,929 & 1,368 & 847 & 614 & 546 \\
\hline $\begin{array}{l}\text { Total power } \\
\text { loss in kW }\end{array}$ & 35 & 109 & 268 & 536 & 186 \\
\hline
\end{tabular}

Therefore, the total power loss of all the transformers $=1,134 \mathrm{~kW}$

Annual energy loss of the transformers

$$
\begin{aligned}
& =1,134 \times 24 \times 365 \\
& =9.9 \mathrm{GWh}
\end{aligned}
$$

\subsection{Overall Energy Flow in the Distribution Network in WPN}

Table 15 summarizes the energy flow in WPNup to the low voltage network level.

Table 15 - Summary of annual energy flow in the distribution system, WPN

\begin{tabular}{|l|c|c|}
\hline & GWh & Percentage \\
\hline $\begin{array}{l}\text { Total annual energy } \\
\text { input to WPN }\end{array}$ & 2,314 & 100.0 \\
\hline $\begin{array}{l}\text { Energy supplied to } \\
\text { LECO }\end{array}$ & 417 & 18.0 \\
\hline $\begin{array}{l}\text { Energy supplied (sales) } \\
\text { to HV bulk consumers }\end{array}$ & 619 & 26.8 \\
\hline $\begin{array}{l}\text { Medium voltage } \\
\text { network loss }\end{array}$ & 26 & 1.1 \\
\hline $\begin{array}{l}\text { Energy supplied (sales) } \\
\text { to LV bulk consumers }\end{array}$ & 485 & 21.0 \\
\hline $\begin{array}{l}\text { Energy loss in LV bulk } \\
\text { consumer transformers }\end{array}$ & 10 & 0.4 \\
\hline $\begin{array}{l}\text { Energy loss in } \\
\text { distribution } \\
\text { transformers }\end{array}$ & 70 & 0.4 \\
\hline $\begin{array}{l}\text { Therefore, } \\
\text { input to LV network }\end{array}$ & 747 & 32.3 \\
\hline
\end{tabular}

Energy loss in distribution network in WPN

$=($ Energy purchased $)-($ Energy sales $)$

$=2,314-(417+619+485+606)$

$=187 \mathrm{GWh}$

Energy loss as a percentage of energy input $=187 / 2,314 \times 100$

$=8.1 \%$

According to the decision on electricity tariffs, allowance of energy for street lighting for DL 2 is $1.37 \%$ of its energy sales [14]. The same basis is used to estimate the consumption of street lamps in WPN. 
Estimated energy consumption of street lamps

$=1,710 \times 1.37 / 100$

$=23.4 \mathrm{GWh}$

Energy loss without street lamps

$=187-23.4=163.6 \mathrm{GWh}$

Percentage energy loss without street lamps

$=163.6 / 2,314 \times 100$

$=7.1 \%$

Aggregate of losses of medium voltage network and all transformers,

$=26+10+10=46$ GWh $(2.0 \%)$

Therefore, energy loss in low voltage network without consumption of street lamps (X)

$=163.6-46=117.6 \mathrm{GWh}$

Therefore, $\mathrm{X}$ as a percentage of total energy input to WPN $=117.6 / 2,314 \times 100=5.1 \%$

Further, it is important to know how much of energy input to the low voltage network is lost.

$X$ as a percentage of energy input to $L V$ Network,

$=117.6 / 747 \times 100$

$=15.7 \%$

Even though LV network loss in the overall provincial energy scenario is less, it is much higher in terms of energy input to the LV network. In order to further segregate the losses in the LV network, the power consumption of electricity meters can be estimated.

The power consumption of a typical single phase electro-mechanical meter used in CEB is around $1 \mathrm{~W}$ [15].

Number of ordinary consumers in WPN

$=541,700$ [11]

Assuming each consumer is installed and measured through a single phase electromechanical meter,

Total power consumption of meters

$=541,700 \mathrm{~W}$

Therefore, annual energy consumption $=4.7 \mathrm{GWh}$

Therefore, the energy loss excluding the power consumption of electricity meters, as a percentage of total energy input to the low voltage network,
$=(117.6-4.7) / 747 \times 100$

$=15.1 \%$

\section{Sample Study on Low Voltage Network Losses}

Low voltage network supplies electricity to ordinary consumers. The ordinary consumers include those supplied under the domestic, religious, small scale industrial and general purpose tariff categories. Street lighting is also in the low voltage network. The share of ordinary consumer electricity sales is about $56 \%$ total electricity sales in the country. Table 16 shows the comparison of electrical energy consumption of the ordinary consumers and the low voltage distribution line lengths in the entire country and the provincial LV network of Western Province North, CEB for the two years.

Table 16 - Details of electricity sales and LV line lengths

\begin{tabular}{|l|c|c|c|c|}
\hline & \multicolumn{2}{|c|}{ Sri Lanka } & \multicolumn{2}{c|}{ WPN } \\
\hline \multicolumn{1}{|c|}{ Year } & $\mathbf{2 0 1 1}$ & $\mathbf{2 0 1 2}$ & $\mathbf{2 0 1 1}$ & $\mathbf{2 0 1 2}$ \\
\hline $\begin{array}{l}\text { Electricity } \\
\text { sales to } \\
\text { LV } \\
\text { ordinary } \\
\text { consumers } \\
\text { in GWh } \\
\text { (A) }\end{array}$ & 5,470 & 5,706 & 683 & 606 \\
\hline $\begin{array}{l}\text { Total } \\
\text { electricity } \\
\text { sales in } \\
\text { GWh (B) }\end{array}$ & 9,972 & 10,389 & 1,735 & 1,710 \\
\hline $\begin{array}{l}\text { A/B } \\
\text { x100\% }\end{array}$ & 56.2 & 56.2 & 39.4 & 35.4 \\
\hline $\begin{array}{l}\text { Total low } \\
\text { voltage } \\
\text { line length } \\
\text { in km }\end{array}$ & 108,886 & 112,995 & 8,121 & 8,329 \\
\hline
\end{tabular}

The objective of this section is to further segregate the losses in a selected area of the LV network into technical and non-technical components.

\subsection{Selection of Substations and Low Voltage Network for Sample Study}

Two substations and the low voltage networks fed by those two substations were selected for the sample study. The details of the substations are in Table 17. The substations have multiple feeders with three phase and single phase feeder segments. The substation is identified in 
the utility context by its unique Substation Identification Number (SIN).

Table 17 - Substations selected for the sample study

\begin{tabular}{|c|c|c|c|c|}
\hline Feeder & $\begin{array}{c}\text { SIN \& } \\
\text { Area }\end{array}$ & $\begin{array}{c}\text { No. of } \\
\text { consu- } \\
\text { mers }\end{array}$ & $\begin{array}{l}\text { Length } \\
\text { of } \\
\text { feeder } \\
\text { sections } \\
\text { (3- Ph.) } \\
\text { (m) }\end{array}$ & $\begin{array}{l}\text { Length of } \\
\text { feeder } \\
\text { sections } \\
\text { (1- Ph.) } \\
\text { (m) }\end{array}$ \\
\hline F1 & \multirow{4}{*}{$\begin{array}{l}\text { G 011, } \\
\text { Gampa- } \\
\text { ha, }\end{array}$} & 190 & 1,500 & 100 \\
\hline F2 & & 155 & 1,400 & 1,000 \\
\hline F3 & & 187 & 1,600 & 500 \\
\hline $\mathrm{F} 4$ & & 238 & 2,000 & 300 \\
\hline F1 & \multirow{3}{*}{$\begin{array}{l}\text { H } 048, \\
\text { Veyang } \\
\text {-oda }\end{array}$} & 230 & 2,800 & 400 \\
\hline F2 & & 124 & 1,400 & 300 \\
\hline F3 & & 11 & 100 & - \\
\hline
\end{tabular}

Table 18 - Calculation of total energy loss of the LV feeders - Substation 1

\begin{tabular}{|l|c|c|c|}
\hline \multicolumn{1}{|c|}{ Substation } & \multicolumn{3}{|c|}{ H048, Veyangoda } \\
\hline Feeder & F 1 & F 2 & F3 \\
\hline $\begin{array}{l}\text { Energy } \\
\text { consumption - } \\
\text { feeder meter }\end{array}$ & 14,925 & 7,092 & 673 \\
\hline $\begin{array}{l}\text { Energy } \\
\text { consumption - } \\
\text { Individual meters }\end{array}$ & 13,311 & 6,349 & 636 \\
\hline $\begin{array}{l}\text { Energy } \\
\text { consumption of } \\
\text { street lamps in } \\
\text { kWh }\end{array}$ & 275 & 118 & 15 \\
\hline $\begin{array}{l}\text { Total energy loss } \\
\text { in kWh (Including } \\
\text { street lamps) }\end{array}$ & 1,614 & 743 & 37 \\
\hline $\begin{array}{l}\text { Percentage energy } \\
\text { loss (Incl. street } \\
\text { lamps ) }\end{array}$ & 10.8 & 10.5 & 5.5 \\
\hline $\begin{array}{l}\text { Total energy } \\
\text { loss(Excluding } \\
\text { street lamps) }\end{array}$ & 1,339 & 625 & 22 \\
\hline $\begin{array}{l}\text { Percentage energy } \\
\text { loss (Excluding } \\
\text { street lamps) }\end{array}$ & 9.0 & 8.8 & 3.3 \\
\hline
\end{tabular}

All the feeders were bare All Aluminium Conductors (AAC, 7/3.40 mm). The total three phase and single phase line lengths were 10.8 $\mathrm{km}$ and $2.6 \mathrm{~km}$ respectively. There were a total of 1,135 consumers in the two substations.

\subsection{Methodology}

In order to find the electrical energy loss in the LV network selected, the methodology adopted is explained below.

- Energy meters were installed near the substation at the beginning of each feeder. The initial active energy reading of each meter was noted.

- Meter readings of all consumers on each LV feeder were obtained.

- A survey was carried out to obtain details of street lamps connected to each feeder.

- The distance of each feeder and spur lines connected were measured.

- The individual service connections and consumer meters on each feeder were inspected and tested.

- After a certain period of time (one month), consumer meter readings on each feeder were obtained.

- The load profile data or averaged over 15 minute time spans were downloaded from the digital meters installed at the feeders. The profiles covered the whole period of measurement.

\subsection{Calculation of Losses}

Initially, the total distribution loss of each feeder was calculated. Then the technical loss (I2R loss) of each LV feeder was estimated. The non-technical loss of each feeder was derived by subtracting the technical loss from the total loss of each feeder. The calculation of energy losses of the two substations are shown in table 18 and 19 , respectively.

\subsubsection{Calculation of technical losses}

The meters of the individual consumers were electro-mechanical and of accuracy class 2 . The electronic or programmable poly-phase meters installed at the feeders were of accuracy class 1 . The outdoor type current transformers used to provide secondary current output to the feeder meters were of accuracy class 1 . The average peak load on each feeder during the period of measurement was obtained from the relevant load profiles downloaded from the feeder meters. The average peak current per phase of each feeder was also calculated. Table 20 shows the results. 
Table 19 - Calculation of total energy loss of the LV feeders - Substation 2

\begin{tabular}{|l|r|r|r|r|}
\hline \multicolumn{1}{|c|}{ Substation } & \multicolumn{4}{|c|}{ G 011, Gampaha } \\
\hline $\begin{array}{l}\text { Feeder } \\
\text { Energy }\end{array}$ & F 1 & F 2 & F 3 & F 4 \\
\hline $\begin{array}{l}\text { consumption - } \\
\text { feeder meter }\end{array}$ & 23,688 & 17,578 & 18,923 & 22,166 \\
\hline $\begin{array}{l}\text { Energy } \\
\text { consumption - } \\
\text { Individual meters }\end{array}$ & 20,383 & 13,431 & 15,560 & 17,637 \\
\hline $\begin{array}{l}\text { Energy } \\
\text { consumption of } \\
\text { street lamps in } \\
\text { kWh }\end{array}$ & 1,071 & 896 & 978 & 946 \\
\hline $\begin{array}{l}\text { Total energy loss } \\
\text { in kWh (Including } \\
\text { street lamps) }\end{array}$ & 3,305 & 4,147 & 3,363 & 4,529 \\
\hline $\begin{array}{l}\text { Percentage energy } \\
\text { loss (Incl. street } \\
\text { lamps ) }\end{array}$ & 14.0 & 23.6 & 17.8 & 20.4 \\
\hline $\begin{array}{l}\text { Total energy } \\
\text { loss(Excluding } \\
\text { street lamps) }\end{array}$ & 2,234 & 3,251 & 2,385 & 3,583 \\
$\begin{array}{l}\text { Percentage energy } \\
\text { loss (Excluding } \\
\text { street lamps) }\end{array}$ & 9.4 & 18.5 & 12.6 & 16.2 \\
\hline
\end{tabular}

Table 20 - Peak loading of the feeders

\begin{tabular}{|c|c|c|c|c|}
\hline $\begin{array}{c}\text { Feeder } \\
\text { Identificat } \\
\quad \text { ion }\end{array}$ & $\begin{array}{c}\text { SIN } \\
\& \\
\text { Area }\end{array}$ & $\begin{array}{c}\text { Avera } \\
\text { ge } \\
\text { daily } \\
\text { peak } \\
\text { load } \\
(\mathrm{kW})\end{array}$ & $\begin{array}{c}\text { Avera } \\
\text { ge } \\
\text { daily } \\
\text { peak } \\
\text { load } \\
(\mathrm{kVA})\end{array}$ & $\begin{array}{l}\text { Averag } \\
\text { e peak } \\
\text { current } \\
\text { (Amp.) }\end{array}$ \\
\hline F1 & \multirow{4}{*}{$\begin{array}{c}\mathrm{G} \\
011\end{array}$} & 67.3 & 71.6 & 103 \\
\hline F2 & & 65.5 & 74.4 & 107 \\
\hline F3 & & 59 & 65.6 & 95 \\
\hline F4 & & 69.3 & 79.7 & 115 \\
\hline F1 & \multirow{3}{*}{$\begin{array}{c}\mathrm{H} \\
048\end{array}$} & 62.5 & 65.8 & 95 \\
\hline F2 & & 30 & 31.8 & 46 \\
\hline F3 & & 3.3 & 3.5 & 5 \\
\hline
\end{tabular}

Under the uniform load distribution model, a load flow analysis was done for each feeder to determine the peak power loss. The software programme "SynerGEE Electric 3.5" was used for the analysis.

Figure 6 shows a screen shot of the load flow analysis results for the feeders. The peak power loss as a percentage of the input peak power demand is indicated in the last column.

\begin{tabular}{|c|c|c|c|c|c|}
\hline \multirow{2}{*}{$\begin{array}{l}\text { Feeder / } \\
\text { Subtran }\end{array}$} & \multicolumn{5}{|c|}{ kW Losses } \\
\hline & A & B & c & Tot & Pet \\
\hline \multicolumn{6}{|c|}{ Feeders for Substation G 011} \\
\hline G 011_Feeder 1 & 1 & 1 & 1 & 4 & $5.0 \%$ \\
\hline G 011_Feeder 2 & 5 & 2 & 2 & 8 & $11.4 \%$ \\
\hline G 011_Feeder 4 & 3 & 2 & 2 & 6 & $8.5 \%$ \\
\hline G 011_Feeder 3 & 3 & 2 & 2 & 7 & $10.1 \%$ \\
\hline G 011 Fdr Totals & 12 & 6 & 6 & 25 & $8.7 \%$ \\
\hline
\end{tabular}

Figure 6 - Percentage peak power losses of the Gampaha G 011 substation

A similar analysis was done for the 3 feeders in the other substation.

Figure 7 shows a screen shot of the load flow analysis results. The peak power loss as a percentage of input peak power demand is indicated in the last column.

\begin{tabular}{|c|c|c|c|c|c|}
\hline \multirow{2}{*}{$\begin{array}{l}\text { Feeder / } \\
\text { Subtran }\end{array}$} & \multicolumn{5}{|c|}{ kW Losses } \\
\hline & A & B & c & Tot & Pct \\
\hline \multicolumn{6}{|c|}{ Feeders for Substation H 048} \\
\hline H 048 Feeder 2 & 0 & 0 & 0 & 1 & $3.1 \%$ \\
\hline H 048 Feeder 3 & 0 & 0 & 0 & 0 & $0.1 \%$ \\
\hline H 048 Feeder 1 & 3 & 2 & 2 & 7 & $11.2 \%$ \\
\hline H 048 Fdr Totals & 4 & 2 & 2 & 8 & $8.3 \%$ \\
\hline
\end{tabular}

Figure 7 - Percentage peak power losses of the Veyangoda H 048 substation

It was required to calculate the average power loss of each feeder. For this, the average load factors and thereby the loss of load factors of the feeders were calculated. Table 21 elaborates the calculation of LF and LLF of the feeders.

Table 21 - Calculation of load factors and loss of load factors of the feeders

\begin{tabular}{|l|c|c|c|c|c|}
\hline Feeder & $\begin{array}{c}\text { Average } \\
\text { Daily } \\
\text { Peak } \\
\text { Demand } \\
(\mathrm{kW})\end{array}$ & $\begin{array}{c}\text { Energy } \\
\text { consump- } \\
\text { tion }(\mathrm{kWh})\end{array}$ & $\begin{array}{c}\text { Period of } \\
\text { measure- } \\
\text { ment in } \\
\text { days }\end{array}$ & LF & LLF \\
\hline F1 & 67.3 & 23,688 & 27 & 0.543 & 0.344 \\
\hline F2 & 65.5 & 17,578 & 27 & 0.414 & 0.220 \\
\hline F3 & 59.0 & 18,923 & 27 & 0.495 & 0.295 \\
\hline F4 & 69.3 & 22,166 & 27 & 0.494 & 0.294 \\
\hline F1 & 62.5 & 14,925 & 21 & 0.474 & 0.274 \\
\hline F2 & 30.0 & 7,092 & 21 & 0.469 & 0.270 \\
\hline F3 & 3.3 & 673 & 21 & 0.405 & 0.212 \\
\hline
\end{tabular}

The calculation of the LLF for the feeder 1 of the G011 substation is shown.

$$
\text { LLF } \quad=0.2 \times 0.543+0.8 \times(0.543)^{2}=0.344
$$


Finally, the energy loss of each feeder under the four models was calculated. The equation below was used for the calculation of energy loss once the peak power loss of each feeder had been calculated.

Energy loss $=$ Peak power loss $\mathrm{x}$ LLF $\mathrm{x}$ period of measurement in hours

The results of the calculations are shown in Table 22.

Table 22 - Calculated energy loss (Technical) of the feeders

\begin{tabular}{|c|c|c|c|}
\hline \multirow{2}{*}{ Feeder } & \multirow{2}{*}{ Substation } & \multicolumn{2}{|c|}{ Energy loss } \\
\hline & & kWh & $\%$ \\
\hline F1 & \multirow{5}{*}{$\begin{array}{c}\text { G 011, } \\
\text { Gampaha }\end{array}$} & 827 & 3.5 \\
\hline F2 & & 1,074 & 6.1 \\
\hline F3 & & 1,139 & 6.0 \\
\hline $\mathrm{F} 4$ & & 1,121 & 5.1 \\
\hline Total & & 4,161 & 5.1 \\
\hline F1 & \multirow{3}{*}{$\begin{array}{c}\text { H 048, } \\
\text { Veyangoda }\end{array}$} & 968 & 6.5 \\
\hline F2 & & 126 & 1.8 \\
\hline F3 & & 0 & 0.1 \\
\hline Total & & 1,095 & 4.8 \\
\hline
\end{tabular}

\subsubsection{Derivation of non-technical losses}

The non-technical loss of each feeder in terms of energy in kWh and as a percentage of total energy input to the feeder is shown in Table 23.

Table 23 - Non-technical losses of the feeders

\begin{tabular}{|c|c|c|c|c|c|}
\hline Feeder & $\begin{array}{c}\text { No. of } \\
\text { meters } \\
\text { tested }\end{array}$ & $\begin{array}{c}\text { No. of } \\
\text { accur-- } \\
\text { atemete } \\
\text { rs }\end{array}$ & $\begin{array}{c}\text { No. of } \\
\text { Defec-- } \\
\text { tive } \\
\text { meters }\end{array}$ & $\begin{array}{c}\text { No. of } \\
\text { tamper } \\
\text { ed } \\
\text { meters }\end{array}$ & $\begin{array}{c}\text { Total } \\
\text { cases } \\
\text { of } \\
\text { NTL }\end{array}$ \\
\hline F1 & 192 & 176 & 12 & 4 & 16 \\
\hline F2 & 155 & 137 & 13 & 5 & 18 \\
\hline F3 & 189 & 180 & 8 & 3 & 11 \\
\hline F4 & 240 & 214 & 22 & 9 & 31 \\
\hline Total & $\mathbf{7 7 6}$ & $\mathbf{7 0 7}$ & $\mathbf{4 8}$ & $\mathbf{2 1}$ & $\mathbf{7 6}$ \\
\hline \% & $\mathbf{1 0 0 . 0}$ & $\mathbf{9 1 . 1}$ & $\mathbf{7 . 1}$ & $\mathbf{1 . 8}$ & $\mathbf{9 . 8}$ \\
\hline F1 & 230 & 213 & 14 & 3 & 17 \\
\hline F2 & 124 & 117 & 5 & 2 & 7 \\
\hline F3 & 11 & 11 & 0 & 0 & 0 \\
\hline Total & $\mathbf{3 6 5}$ & $\mathbf{3 4 1}$ & $\mathbf{1 9}$ & $\mathbf{5}$ & $\mathbf{2 4}$ \\
\hline \% & $\mathbf{1 0 0 . 0}$ & $\mathbf{9 3 . 4}$ & $\mathbf{5 . 2}$ & $\mathbf{1 . 4}$ & $\mathbf{6 . 6}$ \\
\hline
\end{tabular}

Table 24 - Results of meter testing

\begin{tabular}{|c|c|c|c|c|c|}
\hline Feeder & SIN & $\begin{array}{l}\text { Energy } \\
\text { input in } \\
\text { kWh }\end{array}$ & \begin{tabular}{|l} 
Total \\
energy \\
loss in \\
kWh \\
\end{tabular} & $\begin{array}{l}\text { Technic } \\
\text { al loss } \\
\text { in } \mathrm{kWh}\end{array}$ & $\begin{array}{l}\text { Non- } \\
\text { techni- } \\
\text { cal loss } \\
\text { in kWh }\end{array}$ \\
\hline F 1 & \multirow{6}{*}{ G 011} & 23,688 & 2,234 & 827 & 1,407 \\
\hline F 2 & & 17,578 & 3,251 & 1,074 & 2,177 \\
\hline F 3 & & 18,923 & 2,385 & 1,139 & 1,246 \\
\hline F 4 & & 22,166 & 3,583 & 1,121 & 2,462 \\
\hline Total & & 82,355 & 11,453 & 4,161 & 7,293 \\
\hline$\%$ & & 100.0 & 13.9 & 5.1 & 8.9 \\
\hline F 1 & \multirow{2}{*}{ Н 048} & 14,925 & 1,339 & 968 & 371 \\
\hline F 2 & & 7,092 & 625 & 126 & 498 \\
\hline
\end{tabular}

\begin{tabular}{|c|c|c|c|c|}
\hline F 3 & 673 & 22 & 0 & 22 \\
\hline Total & 22,690 & 1,986 & 1,095 & 891 \\
\hline$\%$ & 100.0 & 8.8 & 4.8 & 3.9 \\
\hline
\end{tabular}

The NTL components tabulated above include any errors in the estimation of technical losses, energy losses at service drops and joints, losses in the electricity measuring instruments etc. However, the losses in the electricity meters can be estimated in order to further consolidate on the levels of NTL. Assuming that the power loss of a single phase active energy meter is $1 \mathrm{~W}$ [20].

Power loss of meters in G 011 substation

$$
\begin{aligned}
& =(\text { Number of meters }) \times 1 \mathrm{~W} \\
& =770 \times 1 \mathrm{~W} \\
& =0.77 \mathrm{~kW}
\end{aligned}
$$

Energy loss for 27 days

$$
=499 \mathrm{kWh}
$$

Energy loss as percentage of energy input $=(499 / 82,355) \times 100 \%$

$$
=0.6 \%
$$

Similarly, for the substation in Veyangoda, Energy loss in 375 consumer meters

$$
\begin{aligned}
& =(365 \times 1 \times 24 \times 21 / 1000) \mathrm{kWh} \\
& =184 \mathrm{kWh}
\end{aligned}
$$

Energy loss as percentage of energy input $=184 / 22,690 \times 100 \%$

$$
=0.8 \%
$$

Therefore, NTLs as a percentage of energy input excluding the power consumptions of the meters are $8.3 \%$ and $3.1 \%$ for Gampaha and Veyangoda substations, respectively.

\subsection{Meter Testing Results}

All the consumer meters in the selected two LV networks were tested by CEB staff. The results of the meter testing are shown in Table 24.

The number of defective meters in the entire sample is 74 and it is $6.5 \%$ of the total number of meters tested. The number of cases contributing to non-technical loss is 100 and it is $8.8 \%$ of the total number of meters tested.

\section{Conclusions and Remarks}

Losses in electrical power systems have become a serious problem to utilities worldwide. Amidst the escalating global crisis for energy, the attention of utilities has shifted towards reduction of losses. The economic, financial and social consequences of power system losses are being gradually understood. As such, utilities 
and countries as a whole are devising various measures to arrest losses in electrical power systems. However, an initial and essential step towards reduction of losses is accurately estimating losses.

Losses in electricity distribution represent dominant part in the overall power system losses. In the Sri Lankan context, losses in the distribution system are around $10 \%$ of gross electricity generation when the total losses in generation, transmission and distribution amount to $14 \%$ in 2012 . Though this can be viewed as a reasonably good level, when compared with the power system losses in rest of the developing countries in the region, country need long strides to reach the levels achieved by the developed countries.

In any efforts to arrest losses, it is of paramount importance that the losses are estimated accurately. It is a pre-requisite before developing strategies to counter losses. It is required to segregate distribution losses to identify the losses at different levels.

WPN is a key area in the distribution system of CEB which generate $16 \%$ of its revenue. There are 12 such provinces in the distribution system of CEB. The total energy loss as a percentage of energy input to the province was $7.1 \%$. The medium voltage network loss was $1.14 \%$ of energy input. The losses in the power distribution transformers were at $0.8 \%$. The low voltage network loss as percentage of energy input to the province was $5.1 \%$. However, the same as a percentage of energy input to the low voltage network was $15.7 \%$. This implies that losses in the low voltage network are considerably high, even though its true gravity is not reflected in the overall picture. The situation was subjected to further analysis segregating low voltage network loss into technical and non-technical components. This was done in a selected area of the network, since it was practically difficult to handle the entire network.

The sample study showed an interesting picture which was an eye opener for the utility. Total energy loss in the two substations selected, Gampaha and Veyangoda, were 13.9\% and $8.8 \%$ respectively and technical losses were calculated to be $5.1 \%$ and $4.8 \%$ respectively tow areas. Non-technical losses accounted to $8.9 \%$ and $3.9 \%$ respectively of the energy input to the two substation networks, viz., Gampaha and Veyangoda. Interestingly, the consumption of street lamps was estimated to be $4.8 \%$ and $1.8 \%$ respectively for Gampaha and Veyangoda. Since all consumer meters in the selected networks were tested, test results are interpreted with a view of understanding the contribution of metering problems to nontechnical losses. Following important conclusions can be drawn with regard to the sample study.

- $\quad$ Street lamp consumptions can be very high as they are not metered or billed properly. Therefore, it is recommended to adopt suitable methods to monitor and record the consumption of street lamps.

- Presence of defective meters contributes significantly to NTL. Well organized regular meter testing and replacement programmes are essential to overcome the problem.

- Utility must adopt proper seal management systems, and refurbish meter installation fully without correcting only the meter, to prevent or minimize avenues for unauthorized access.

- Proper sealing and installation practices should be used right at the time new connections are given to prevent addition of new cases which might contribute to NTL.

- $\quad$ Set up standards for regular meter testing programmes at utility or regulator level.

- It is required to device programmes to analyse consumer consumption patterns to identify power pilferages.

It is recommended to have broader surveys to determine low voltage network losses such that entire network can be modelled with sufficient accuracy. It will enable the utility to implement loss reduction measures very effectively.

\section{References}

1. Sustainable Energy Authority Sri Lanka. Electricity data overview [Online]. Available: http://www.info.energy.gov.lk.

2. Navini, J. P. et al., “Technical and Non-Technical Losses in Power System and its Economic Consequences in Indian Economy," J. International Journal of Electronics and Computer, Vol. 1, no. 2, pp. 757-761, April, 2012.

3. Public Utilities Commission Sri Lanka, "Transmission System Performance Report Sri Lanka 2012," PUCSL, Colombo, Rep., 2012. 
4. Public Utilities Commission Sri Lanka, "Performance Report of Distribution Licensees 2012,” PUCSL, Colombo, Rep., 2012.

5. Millard, R. and Emmerton, M. "Non-Technical Losses - How do other Countries Tackle the Problem," in Proc. Association of Municipal Electricity Utilities Southern Africa Conf., Port Elizabeth, 2009.

6. Planning and Development Branch Distribution Region 2 Ceylon Electricity Board, "Medium Voltage Development Studies Region 22012 2021," CEB, Colombo Sri Lanka, CEB, Mar. 2013.

7. Planning and Development Branch Distribution Region 2 Ceylon Electricity Board. "Medium Voltage Development Studies Region 22011 2020," CEB, Mar. 2013.

8. Jayasinghe, J. P. R. "Segregation and Analysis of Distribution Losses and Mitigating Techniques," M. S. Thesis, Dept. Elect. Eng., Univ. of Moratuwa, Moratuwa, Sri Lanka, 2005.

9. Gray, C. B., "The Transformer," in Electrical Machines and Drive Systems, low priced ed. Singapore, Singapore: Longman, 1989, pp. 100130.

10. Gilby, K., (2011, Feb. 28), Network Loss Factor Methodology 2011 -2012 [Online]. Available: http://www.topenergy.co.nz.

11. Aurora Energy Ltd. (2012, April 1). Loss factors [Online]. Available: http:// www.auroraenergy.co.nz.

12. Keresting, W. H., "Approximate Methods of Analysis," in Distribution System Modeling and Analysis, Florida: CRC Press, 2001, pp. 35-71.

13. Transmission and Generation Planning Branch Transmission Division Ceylon Electricity Board, "Long Term Transmission Development Plan 2011 - 2020,", CEB, May 2013.

14. Public Utilities Commission Sri Lanka. "Decision on Electricity Tariffs (Effective from 01st January 2011), PUCSL, Colombo, Rep. Jan. 2011.

15. Electricity metering equipment (a.c.) Particular requirements, IEC standard 62053, 2003.

16. Ceylon Electricity Board, Statistical Digest 2012.

17. Ceylon Electricity Board, Statistical Digest 2011. 